\title{
Indications for Human Albumin Infusion in a Neonatal Population: A Single Center Experience
}

\author{
Halil DEGIRMENCIOGLU1, Birgul SAY², Serife Suna OGUZ \\ Aydin, Turkey
}

ABSTRACT:

OBJECTIVE: To evaluate the indications for human albumin infusion, the suitability of albumin infusion in neonatal intensive care units and neonatal outcomes after human albumin administration.

STUDY DESIGN: Infants who had hypoalbuminemia (albumin level $<20 \mathrm{~g} / \mathrm{L}$ ) and were given albumin infusion at any time during hospitalization between December 2012 and December 2013 were included in the study. Mortality (group 1 (alive), group 2 (died during hospitalization)) and morbidities were recorded. Demographic properties were assessed retrospectively.

RESULTS: 38 neonates required human albumin transfusion therapy 61 times during the study, 89.5\% were premature birth. $9(23.7 \%)$ of 38 patients underwent major surgery. Group I =survived and are currently alive $(n=22,58 \%)$, Group $\|=$ died during hospitalization $(n=16,42 \%)$. In the groups, aspartate aminotransferase, creatinine and albumin levels were significantly different before and after infusion.

CONCLUSION: The value of human albumin in the clinical setting continues to be controversial and well-designed guidelines for its use in NICUs should be established for the neonatal period.

Keywords: Newborn, Albumin, Outcome

Gynecol Obstet Reprod Med 2018;24(1)47-51

\section{Introduction}

Human albumin (HA) is the major protein produced by the liver, whose main function is the regulation of capillary oncotic pressure (1). This oncotic pressure is low both in the fetus and the neonate because of low plasma albumin concentrations, which increase from $2 \mathrm{~g} / \mathrm{dL}$ at 24 weeks' gestation to

\footnotetext{
${ }^{1}$ Division of Neonatology Aydın Maternity and Teaching Hospital, Aydin

${ }^{2}$ Division of Neonatology Derince Education and Research Hospital, Kocaeli

${ }^{3}$ Division of Neonatology Zekai Tahir Burak Maternity Teaching Hospital, Ankara

Address of Correspondence: Birgul Say

Division of Neonatology, Derince

Education and Research Hospital, 41900 Derice, Kocaeli Turkey

birgullivasay@gmail.com

Submitted for Publication:

22.09.2017

Accepted for Publication:

14.12.2017
}

\begin{tabular}{|c|c|}
\hline & Access this article online \\
\hline $\begin{array}{c}\text { Quick Response Code: } \\
\text { Website: www.gorm.com.tr } \\
\text { e- mail: info@gorm.com.tr }\end{array}$ & \begin{tabular}{c} 
DOI:10.201613/GORM.2017.738 \\
\cline { 2 - 3 }
\end{tabular} \\
\hline
\end{tabular}

How to cite this article: Degirmencioglu H. Say B. Oğuz SS. Indications for Human Albumin Infusion in a Neonatal Population: A Single Center Experience. Gynecol Obstet Reprod Med 2018;24(1):47-51 just above $3 \mathrm{~g} / \mathrm{dL}$ at term delivery. Serum albumin levels in preterm infants are significantly lower than those in term infants (2). In addition to the binding and transport functions of albumin, it also has a role as a free radical scavenger and has anticoagulant effects (3).

Human albumin infusions are frequently administered to treat hypoalbuminemia (HAlb) in the neonatal intensive care unit (NICU). In addition, HA has been studied to add to hyper alimentation solutions, however, it has been shown that this could increase the potential for growth of bacteria or fungi. Therefore, it is recommended that HA should be administered separately from parenteral solutions and has been used for metabolic acidosis treatment and as part of the neonatal resuscitation of a depressed infant in the labor ward $(4,5)$. It has been shown that routinely increasing albumin concentration in preterm infants by infusion has no therapeutic benefit $(6,7)$.

We conducted a retrospective study to evaluate indications for HA infusion and the suitability of its use in the NICU during hospitalization. A secondary aim was to evaluate the effect of HA infusion on neonatal outcomes.

\section{Material and Method}

This was a retrospective study in a single level III Turkish NICU at Zekai Tahir Burak Maternity Teaching Hospital between December 2012 and December 2013 in Turkey. We enrolled infants according to the following inclusion criteria: 1) 
Admission to the NICU after birth, 2) Infants who had HAlb and were given albumin infusion during any time of hospitalization. HAlb is defined as $<20 \mathrm{~g} / \mathrm{L}$ and $20 \%$ albumin was given to increase serum albumin levels or to treat edema. The study was approved, as appropriate, by the hospital local educational planning commission before data collection. Demographic data, gestational history of infants, including birth weight, gestational age, gender, Apgar scores, maternal history (amnion abnormalities, multiple pregnancy, diabetes mellitus, preeclampsia, use of antenatal steroids, etc.) presence of other neonatal morbidities such as surgical procedures, respiratory distress syndrome (RDS), patent ductus arteriosus (PDA), intraventricular hemorrhage (IVH), bronchopulmonary dysplasia (BPD), necrotizing enterocolitis (NEC) and retinopathy of prematurity (ROP), laboratory tests (before and after albumin infusion; liver and renal function tests, serum albumin and total protein levels), nutritional status and long term outcomes were recorded. Mortality and duration of hospitalization were also recorded. Infants were classified into two groups: 1) survivors given HA infusion (Group I), and 2) non-survivors who were given albumin infusion (Group II). Subgroup analyses were then performed.

\section{Statistical analyses}

Statistical analyses were performed using the commercial package SPSS for Windows version 17.0 (Chicago, IL, USA). Values for numerical variables were provided as mean \pm standard deviation or median (minimum-maximum), depending on normality of distribution. Categorical variables were given as numbers and total percentages. For numerical variables, two-group comparisons were made using Mann Whitney U test, whereas Kruskal Wallis test was preferred for multiple comparisons. Comparisons between groups for categorical variables were made using Chi-square $\left(\chi^{2}\right)$ test. Comparison between groups and changes in time were evaluated using repeated measures ANOVA test. A p-value of less than 0.05 was considered indicative of statistical significance.

\section{Results}

Over a period of 1-year (from December 2012 to December 2013), a total of 2234 inborn neonates were admitted to the NICU, and 38 neonates required HA transfusion therapy 61 times during the study. Maternal risks, and natal and postnatal characteristics of infants $(n=38)$ treated with albumin at any time during the hospital stay in the NICU are summarized in table 1 .

Among the treated neonates $89.5 \%$ were premature. RDS was the most frequent indication for hospitalization (68.4\%), followed by hypoglycemia (34.9\%) and congenital anomalies (13.1\%). Single dose surfactant requirement via endotracheal route to the patients with a diagnosis of RDS was 24/26 (92\%). Requirement of multiple doses of surfactant treatment for RDS was $5 / 24$ (20\%).

$43.8 \%$ of premature infants $(14 / 32)$ at 34 weeks or less gestational age who were given HAlb treatment died, and other morbidities are summarized in table 2. 9 (23.7\%) of 38 patients underwent major surgery during hospitalization in the NICU (Table 3).

Table 1: Maternal risks, natal, and postnatal characteristics of treated infants $(n=38)$

\begin{tabular}{|c|c|}
\hline Maternal Factors & Values \\
\hline Maternal age (year) ${ }^{a, b}$ & $30.7 \pm 6.8(20-48)$ \\
\hline$\geq 30$ years $^{c}$ & $10 / 38(26.3)$ \\
\hline \multicolumn{2}{|l|}{ Maternal historyc } \\
\hline - Polyhydroamnios & $3 / 38(7.9)$ \\
\hline - Oligohydramniosis & $2 / 38(5.3)$ \\
\hline - Multiple births & $7 / 38(18.4)$ \\
\hline - Gestationel Diabetes & 2/38 (5.3) \\
\hline - Preeclampsia & $14 / 38(36.8)$ \\
\hline \multicolumn{2}{|l|}{ Neonatal Factors } \\
\hline - Gestational age, weeks ${ }^{a, b}$ & $29.6 \pm 4.5(23-40)$ \\
\hline$\leq 34$ weeks'c & $32 / 38(84.2)$ \\
\hline 35-36 weeks'c & $2 / 38 \quad(5.2)$ \\
\hline$\geq 37$ weeks'c & $4 / 38 \quad(10.6)$ \\
\hline - Birth weight $(g)^{a, b}$ & $1398 \pm \pm 787(560-3700)$ \\
\hline - Male gender ${ }^{c}$ & $18 / 38(47.4)$ \\
\hline - Cesarean deliveryc & $31 / 38(81.6)$ \\
\hline - APGAR score $\left(1^{\text {th }} \min \right)^{b}$ & $5(1-7)$ \\
\hline
\end{tabular}

a: Values are given as mean \pm standard deviation, $b$ : Values are given as median (min - max), c: Values are given as percentage 
Table 2: Morbidities of preterm infants at 34 weeks or less gestational age of study population $(n=32)$.

\begin{tabular}{lc}
\hline Morbidities & $\mathrm{n}(\%)$ \\
\hline - PDA & $17 / 32(52.1)$ \\
- BPD & $9 / 32(28.1)$ \\
- ROP & $9 / 32(28.1)$ \\
- Proven Sepsis & $14 / 32(43.8)$ \\
- Renal failure & $8 / 32(25)$ \\
- Severe IVH & $5 / 32(15.7)$ \\
- NEC (with surgery) & $3 / 32(9.3)$ \\
- Surgery (without NEC) & $4 / 32(12.5)$ \\
- Cholestasis & $7 / 32(21.9)$ \\
\hline
\end{tabular}

All data presented as number ( $n$ ) with the percentage in parenthesis.

PDA: Patent ductus arteriosus, BPD: Bronchopulmonary dysplasia, ROP: Retinopathy of prematurity, IVH: Intraventricular haemorrhage, NEC: Necrotizing enterocolitis.

Table 3: Patients underwent major surgery during hospitalization at neonatal intensive care unit

\begin{tabular}{|c|c|c|c|c|}
\hline Patient no. & Gestational age(weeks')/ birth weight & Indication & Surgery & Outcome \\
\hline 1 & 27 weeks' / 860 g & $\mathrm{NEC}^{*}$ & Abdominal surgery, ileostomy & Alive \\
\hline 2 & 27 weeks' /725 g & Reflux & Abdominal surgery & Exitus \\
\hline 3 & 27 weeks' / $1790 \mathrm{~g}$ & Intestinal atresia & Abdominal surgery, ileostomy & Alive \\
\hline 4 & 30 weeks' / $1200 \mathrm{~g}$ & NEC & Abdominal surgery, ileostomy & Exitus \\
\hline 5 & 37 weeks' / $2770 \mathrm{~g}$ & Intestinal atresia & Abdominal surgery, ileostomi & Exitus \\
\hline 6 & 28 weeks' / $1255 \mathrm{~g}$ & Hydrocephalus & V/P shunt ${ }^{* *}$ & Alive \\
\hline 7 & 39 weeks' / $3110 \mathrm{~g}$ & Intestinal atresia & Abdominal surgery & Alive \\
\hline 8 & 31 weeks' / $1200 \mathrm{~g}$ & Intestinal atresia & Abdominal surgery, ileostomy & Alive \\
\hline 9 & 28 weeks' / $1090 \mathrm{~g}$ & NEC & Abdominal surgery, ileostomy & Exitus \\
\hline
\end{tabular}

${ }^{*} N E C$ : Necrotizing enterocolitis, ${ }^{* *}$ V/P: Ventriculo-peritoneal

According to mortality, infants receiving HA transfusion were divided into two groups: (Group I =survived and are currently alive $(\mathrm{n}=22,58 \%)$, Group $\mathrm{II}=$ died during hospitalization $(\mathrm{n}=16,42 \%))$. There was no difference between maternal risks, natal and postnatal characteristics between the two groups ( $p>0.05$ ). Serum albumin values were similar in both groups before albumin transfusion (Table 4). A comparison of diseases causing HAlb or therapies among groups revealed assisted ventilation support, time to not receiving enteral feeding, and renal failure before treatment were significantly higher in infants who died during hospitalization (Table 4).

Laboratory test analysis and results among groups before and after albumin treatment are summarized in table 5 . Comparing the laboratory data between the two groups before and after albumin infusion: in Group I, aspartate aminotransferase, creatinine, and albumin levels were significantly different before and after infusion $(\mathrm{p}=0.02, \mathrm{p}=0.04$ and $\mathrm{p}=0.00$, respectively), in Group II, only serum albumin levels were significantly different $(\mathrm{p}=0.02)$, but there were no differences between other repeated values (Table 5).

Table 4: Comparison of therapy period and outcomes according to groups.

\begin{tabular}{|c|c|c|c|}
\hline Parameters & Group I $(n=22)$ & Group II $(n=16)$ & $p$ \\
\hline Mechanical ventilation (days)* & $11(4.5-14)$ & $25(7.2-50)$ & 0.02 \\
\hline Continuous positive airway pressure therapy (days)* & $3(2-8.7)$ & $4.5(4-10)$ & 0.44 \\
\hline Duration of oxygen supplementation (days) ${ }^{\star}$ & $10(3.7-27)$ & $6(1.7-14)$ & 0.13 \\
\hline Time to not receiving enteral feeding (days) ${ }^{*}$ & $5(5-15)$ & $17.5(5-30)$ & 0.07 \\
\hline Time to first enteral feeding (days) ${ }^{\star}$ & $16.5(13.5-27)$ & $14(10-35)$ & 0.60 \\
\hline NICU stay (days) ${ }^{*}$ & $87(48.2-102)$ & $42.5(8-87)$ & 0.03 \\
\hline Renal failure, $\mathrm{n}(\%)$ & $1 / 22(4.5)$ & $8 / 16(50)$ & 0.02 \\
\hline
\end{tabular}

$p<0.05$ is significant. *Median, (IQR, interquartile range). NICU: Neonatal intensive care unit 
Table 5: Laboratory analysis of all groups before and after albumin treatment

\begin{tabular}{|c|c|c|c|c|}
\hline & & Group I & Group II & $p$ value* \\
\hline \multirow[t]{2}{*}{ AST (U/L) } & Before treatment & $68(49-111)$ & $41(25.5-42.1)$ & 0.78 \\
\hline & After treatment & $62(52-80)$ & $64(26-110)$ & 0.75 \\
\hline \multirow[t]{2}{*}{ ALT (U/L) } & Before treatment & $41(25-42.1)$ & $42(22-49.5)$ & 0.69 \\
\hline & After treatment & $32(24-42)$ & $43(26-52)$ & 0.23 \\
\hline \multirow[t]{2}{*}{ Albumin (mg/dl) } & Before treatment & $1.79(1.57-1.86)$ & $1.84(1.62-1.9)$ & 0.46 \\
\hline & After treatment & $2.4(2.1-2.5)$ & $2.32(2.1-2.4)$ & 0.40 \\
\hline \multirow[t]{2}{*}{ Serum BUN (mg/dl) } & Before treatment & $34(25-56)$ & 80 (54-99) & 0.001 \\
\hline & After treatment & $40(21.2-63)$ & $80(65.8-100)$ & 0.001 \\
\hline \multirow[t]{2}{*}{ Serum Kreatinin $(\mathrm{mg} / \mathrm{dl})$} & Before treatment & $0.53(0.31-0.8)$ & $1.1(0.8-1.8)$ & 0.02 \\
\hline & After treatment & $0.6(0.4-0.8)$ & $1.2(0.9-1.9)$ & 0.00 \\
\hline
\end{tabular}

${ }^{*} p<0.05$ is significant. AST: Aspartate aminotransferase, ALT: Alanine aminotransferase, BUN: Blood urea nitrogen

\section{Discussion}

Albumin is synthesized only in a suitable nutritional, hormonal and osmotic environment. The colloid osmotic pressure of the interstitial fluid bathing the hepatocyte is the most important regulator of albumin synthesis (8). Therefore, measuring serum albumin level is a clinical indication for assessing nutritional status and liver function and is also essential in understanding and evaluating the etiology of edema (9).

In the adult population, it has been shown that the most common indications for administration of exogenous albumin are hypotension in hemodialysis $(18.9 \%)$, volume replacement (15\%) and correction of HAlb (14.8\%). In 9.4\% of cases, no indication for HA was identified (4). In the Cochrane Review, these indications were examined and compared for mortality versus cheaper alternatives, and it was shown that there was no evidence that albumin reduced mortality in critically ill patients with burns and HAlb (10). A meta-analysis of randomized, controlled trials showed that except for patients with ascites, the use of HA was not associated with significantly improved morbidity (11).

One of the remarkable findings of our study was that nine infants $(24 \%)$ who had HAlb required surgery during hospitalization. The majority of surgical causes for infants in the study were ileal atresia and NEC. The other reason for surgery was hydrocephalus, which required the placement of a ventriculo-peritoneal shunt. This study showed that HAlb is a common finding in surgical neonates on parenteral nutrition. Not only insufficient enteral feeding before and after surgery, but also HAlb may result from inadequate albumin synthesis, increased catabolism, extracorporeal losses, trans-capillary leak or dilution (12).

In the presence of septicemia or severe metabolic stress, increased protein catabolism occurs. Serum albumin catabolism has not been well characterized, although it is thought to occur in all tissues, especially the skin, muscles and liver (13). It was unlikely that this was the cause of HAlb because the in- cidence of septicemia was similar and not increased in infants with HAlb.

The majority of the performed research in the literature was conducted with the adult population. Studies that investigated the effects of the use of albumin in infants for indications or outcome are very few. Many studies have been done on the usefulness of albumin infusion in neonates. It has been given as a part of the initial resuscitation process in severely asphyxiated term infants (14), in response to metabolic acidosis $(\mathrm{pH}<7.25)$ in ventilated, VLBW infants with normal blood pressure (15), and for assessing the suitability for blood pressure improvement in infants $(16,17)$. After a thorough assessment for the underlying cause of HAlb, we corrected HA in all our infants.

In adult patients, there is a well-recognized inverse relationship between serum albumin level and clinical outcome $(17,18,19)$. Serum albumin predicts survival because it reflects not only nutrition but also systemic disease. In this study, mortality was significantly higher among HAlb infants. This seemed to be temporally and causally related to prior worsening renal function or acute renal failure. Renal function tests after albumin infusion were not statistically significant, but there was a deterioration detected. It may be speculated that a relationship exists between mortality and gradually adversely affected renal function.

In this study, all of the infants with HAlb received exogenous albumin to correct the low serum albumin level.

Fluid overload is one of the potential side effects of albumin administration. Albumin is a blood product and therefore carries the potential risk of infection and many adverse reactions. We noted no side effects with albumin administration.

Our study has a number of limitations, including its retrospective nature, small sample size and the fact that it was conducted at a single institution. Further well-designed prospective multicenter trials should be performed to understand the effect of albumin infusion on neonatal outcomes. 
On the basis of our findings, serum albumin levels did not differ between the groups, but longer inadequate enteral feeding and worsening renal function were more frequent in infants who died during hospitalization. Overall, the presence of acute renal failure or worsening renal function before HA administration has been associated with mortality. Infants with prior worsening renal function may have a greater risk of HA over time.

In the presence of prematurity ( $<34$ weeks), long-term problems such as malnutrition, prolonged mechanical ventilator support or prior renal failure, serum albumin levels should be monitored closely. In such cases, planning protein supplements might be more useful. For this, further prospective studies are needed.

In conclusion, the value of HA in the clinical setting continues to be controversial and well-designed guidelines for its use in the NICU should be established for the neonatal period. We should recognize that HAlb is a marker of an underlying disease and not a cause of it.

: All of the authors have no financial relationships relevant to this article to disclose.

All of the authors have no conflicts of interest relevant to this article to disclose.

This study was funded by the Zekai Tahir Burak Maternity Teaching Hospital Neonatology Department and Blood Center Department.

\section{References}

1. Vanek V. The use of serum albumin as a prognostic or nutritional marker and the pros and cons of IV albumin therapy. Nutr Clin Pract 1998;13:110-122.

2. Takagi K, Tanaka H, Nishijima S, Masaoka N, Miyake Y, Sakata H, Satoh K. Fetal blood values by percutaneous umbilical blood sampling. Fetal Ther 1989;4(2-3):152160.

3. Margarson MP. Soni N. Serum albumin: touchstone or totem? Anaesthesia 1998;53(8):789-803.

4. Roberton NR. Use of albumin in neonatal resuscitation. Eur J Pediatr 1997;156(6):428-431.

5. Mirtallo JM, Caryer K, Schneider PJ, Ayers L, Fabri PJ. Growth of bacteria and fungi in parenteral nutrition solutions containing albumin. Am J Hosp Pharm 1981; 38(12):1907-1910

6. Lay KS, Bancalari E, Malkus H, Baker R, Strauss J. Acute effects of albumin infusion on blood volume and renal function in premature infants with respiratory distress syndrome. J Pediatr 1980;97(4):619-623.

7. Greenough A, Morley CJ, Roberton NRC. Acute respiratory disease in the newborn. In: Roberton NRC, editor(s). Textbook of Neonatology. $2^{\text {nd }}$ edition. London: Churchill
Livingston 1992;385-504.

6. Greenough A, Roberton NRC. Acute respiratory disease in the newborn. In: Rennie JM, Roberton NRC, editor(s). Textbook of Neonatology. $3^{\text {rd }}$ edition. Edinburgh: Churchill Livingston 1999;481-607.

7. Jardine LA, Jenkins-Manning S, Davies MW. Albumin infusion for low serum albumin in preterm newborn infants. Cochrane Database Syst Rev 2004;3:CD004208

8. Yamauchi A, Fukuhara Y, Yamamoto S, Yano F, Takenaka $\mathrm{M}$, Imai $\mathrm{E}$, et al. Oncotic pressure regulates gene transcriptions of albumin and apolipoprotein B in cultured rat hepatoma cells. Am J Physiol 1992;263(2):397-404.

9. Reading RF, Ellis R, Fleetwood A. Plasma albumin and total protein in preterm babies from birth to eight weeks. Early Hum Dev 1990;22(2):81-87.

10. Roberts I, Blackhall K, Alderson P, Bunn F, Schierhout G. Human albumin solution for resuscitation and volume expansion in critically ill patients. Cochrane Database Syst Rev 2011;11:CD001208

11. Vincent JL, Sakr Y, Reinhart K. 'Sepsis Occurrence in Acutely Ill Patients' Investigators. Is albumin administration in the acutely ill associated with increased mortality? Results of the SOAP study. Crit Care 2005;9(6):745-754.

12. Kaminski MV, Williams SD. Review of the rapid normalization of serum albumin with modified total parenteral nutrition solutions. Crit Care Med 1990;18(3): 327-335.

13. Strobel JL, Cady SG, Borg TK, Terracio L, Baynes JW, Thorpe SR. Identification of fibroblasts as a major site of albumin catabolism in peripheral tissues. J Biol Chem 1986;261(17):7989-7994.

14. Fan C, Phillips K, Selin S. Serum albumin: new thoughts on an old treatment. BCMJ 2005;47(8):438-444.

15. Belgaumkar A, Greenough A, Kavvadia V, Dimitriou G. Metabolic acidosis: response to albumin infusion. Eur J Pediatr 1998;157(6):520-521.

16. Emery EF, Greenough A, Gamsu HR. Randomized controlled trial of colloid infusions in hypotensive preterm infants. Arch Dis Child 1992;67(10):1185-1188.

17. So KW, Fok TF, Ng PC, Wong WW, Cheung KL. Randomised controlled trial of colloid or crystalloid in hypotensive preterm infants. Arch Dis Child Fetal Neonatal Ed 1997;76(1):43-46.

18. Gibbs J, Cull W, Henderson W, Daley J, Hur K, Khuri SF. Preoperative serum albumin level as a predictor of operative mortality and morbidity: results from the National VA Surgical Risk Study. Arch Surg 1999;134(1):36-42.

19. Vincent JL, Dubois MJ, Navickis RJ, Wilkes MM. Hypoalbuminemia in acute illness: is there a rationale for intervention? A meta-analysis of cohort studies and controlled trials. Ann Surg 2003;237(3):319-334. 